on it is essential that there should be a sanction, such as automatic reinstatement of any suspended doctor if the health authority is dilatory. Furthermore, in making these time limits one key stage is missing - that between the doctor being suspended and the health authority deciding that a prima facie case exists against the doctor. This stage can take years because health authorities will recklessly suspend doctors on the basis of rumour and then have to labour hard to find something, anything, to justify the suspension and to avoid legal redress by the aggrieved doctor. Nevertheless, we agree with Dr Forsythe in welcoming the proposals for a graded treatment for graded degrees of misconduct.

Dr Forsythe seems to think that the paragraph 190 procedure is a true appeal mechanism. But the Minister of Health has recently ignored the verdict and dismissed a doctor who won his appeal. Surely the verdict of any appeal committee should be binding until overturned by a higher authority? Because the NHS is a monopoly employer all hospital doctors must have the right to appeal to the Secretary of State against any dismissal by a health authority. That is not the case at the present. Any doctor can be summarily dismissed without warning on any charge and is denied the right of appeal. This interpretation of the law has recently been upheld in the High Court.

The joint working party still favours secret trials of doctors-Why? The disciplinary hearings of the General Medical Council are heard in public, and as a result the profession is held high in the public esteem for its efforts in keeping its house in order. Lord Justice Brown in his judgment of a disciplinary case against a doctor in 1986 stated: "The maxim that justice must not only be done but must manifestly be seen to be done applies in full measure" (Crown Office 595/86). In that judgment he was only following article 6 (i) of the European Charter of Human Rights. All inquiries of suspended doctors should be held in public. Only the guilty have something to fear, and in condoning secret trials the profession will, rightly or wrongly, be seen as conspiring against the public weal.

The Society of Clinical Psychiatrists has produced a code of conduct about suspended doctors. The main thrusts of the proposals are that, except in an emergency, doctors may not be suspended until after investigation, that suspensions should follow the Advisory, Conciliation, and Arbitration Service code of practice, that the NHS should not usurp the function of the General Medical Council in deciding if a doctor is professionally incompetent or guilty of professional misconduct, that HM (61) 112 should be abolished, that the verdict of any appeal mechanism should be binding on both sides, and that all changes should conform to the European Charter of Human Rights and to the European employment laws.

H JACOBS

Colchester

P J TOMLIN

Birmingham

1 Forssthe M. Real progress with disciplining doctors. Br Med $\mathcal{J}$ 1988:297:1+87-8. (10 December.

\section{Lectures and lecturers}

SIR,-The thoughts expressed by Professor Michael Shepherd raise some interesting questions.' Taking as his text "Why lecture?", a quotation from an essay by Virginia Woolf, he considers various teaching situations and seems to adopt the view that lectures are redundant. In this, of course, he has the distinguished support of Alice in Wonderland, who told her tutor, "I think I should understand that better,' Alice said very politely, 'if I had it written down: but I'm afraid I can't quite follow it as you say it.",

The question which has been worrying me over the holiday is why do audiences continue to assemble for lectures offered by learned societies, by postgraduate medical centres, and at numerous meetings throughout the year, and why do speakers continue to appear? A film or television recording can offer an alternative to the presence of a lecturer but only if the material is suitably adapted for the medium; a recording of a man reading his notes - perhaps with a few slides on the screen - is no substitute.

The paper concludes with a quotation from $\mathrm{Dr}$ Johnson, suggesting that reading a book is better than attending a lecture on the subject. This is not borne out by experience. After lecturing for some years on a (non-medical) subject I was encouraged to write a book on it; rather than there being reduction in the number of times I am invited to address meetings, requests have quadrupled since publication. Professor Shepherd touches on one advantage of a lecture over a book - the presentation can be related to the particular needs of the audience. Indeed, the speaker can benefit too because questions and discussion during a lecture can highlight those parts of the talk which could be improved.

Doctors, it seems, will continue to attend meetings expectantly, even though they have often been disappointed by lectures in the past.

London $\mathrm{N} 1+6 \mathrm{QG}$

MICHAEL ESSEX-LOPREST

1 Shepherd M. Lectures and lecturers. Br Med f 1988;297:162-3. 24-31 December

2 Carroll L. Alice's adventures in wonderland.

Essex-Lopresti $M$. Illuminating an address: a guide for speaker at medical meetings. Hid Educ 1980;14:8-11.

\section{Drug Points}

\section{Widespread tremor after injection of sodium calcitonin}

DrS I I CONGET, J VENDRELL, I HALPERIN, and E ESMATJES (Endocrinology Unit, Hospital Clinic, University of Barcelona, Barcelona 08036, Spain) write: Synthetic calcitonins are effective for diseases associated with an increase in bone resorption and turnover-for example, Paget's disease, hypercalcaemia of malignancy, and primary hyperparathyroidism. Side effects occur in up to $10 \%$ of patients, and, although often mild, they are severe enough to stop treatment in over a third of patients. ${ }^{\prime 2}$ We here describe a case of widespread tremor after subcutaneous administration of salmon calcitonin

A 35 year old insulin dependent diabetic woman was admitted with a three week history of painful ankle. After clinical and radiological evaluation we diagnosed reflex dystrophy of the ankle. Rest and salmon calcitonin were prescribed. All biochemical and haematological values at admission were normal. Within about 90 minutes of the first subcutaneous injection of $100 \mathrm{IU}$ of salmon calcitonin (Sandoz) the patient developed a widespread fine tremor. It affected the head and the arms and legs, which were equally affected, though the tremor was most evident on the distal parts of the limbs. The tremor lasted about an hour: Similar tremors occurred after subcutaneous injection of the same dose of another batch of the same calcitonin and another make of salmon calcitonin (Armour). Tremor did not occur after placebo. Serum calcium concentrations before and during (90 minutes after the injection) the episodes of tremor were normal.

The most common side effects of salmon calcitonin include gastrointestinal symptoms (nausea vomiting, abdominal pain, diarrhoea) and vascula symptoms such as facial flushing and tingling of the hands. Erythema and pain at injection sites, polyuria, rash, and an unpleasant metallic taste have also been described. They usually occur within one hour of injection and may be diminished by use of the subcutaneous rather than the intramuscular route. ${ }^{3}$ In our patient the timing and repeated appearance of widespread tremor after subcutaneous injection of salmon calcitonin suggest that the association was not fortuitous. There is evidence that during the process of producing synthetic calcitonins impurities (erroneous peptides) can appear, which vary with the batch and the make. Some side effects of these products therefore relate to these substances. ${ }^{4}$ In our patient, however, we observed widespread tremor after several batches and two different makes of salmon calcitonin, but the serum calcium concentration was normal throughout. On the other hand, the calcitonin gene encodes the precursor peptides for calcitonin and calcitonin gene related peptide. The calcitonin pathway predominates in the C cells of the thyroid and the gene related peptide in the nervous system. The gene related peptide shows greater homology with salmon calcitonin than the human calcitonin, and this homology has been invoked to explain the putative effects of salmon calcitonin on the nervous sytem. ${ }^{56}$ This point is very attractive as a pathogenic hypothesis in our case, although the role of calcitonin gene related peptide in normal human physiology is controversial. Nevertheless, widespread tremor should be considered as an additional side effect of salmon calcitonin treatment.

1 McIntyre I, Evans IMA, Hobitz HHG, Joplin GF, Stevenson C. Chemistry, physiology and therapeutic applications of calcitonin. Arthritis Rheum 1980;23:1139-47.

Singer FR, Fredricks RS, Minkin C. Salmon calcitonin therapy for Paget's disease of bone. Arthritis Rheum 1976;23:1148-54.

Gennari C, Passeri M, Chierichetti SM, Piolini M. Side effects of synthetic salmon and human calcitonin. Lancet 1983;i:594-5.

Bangham DR, Zanelli JM. Side effects of calcitonins. Lancet 1983;i:926-7.

5 Tschopp FA, Henke H, Petermann JB, et al. Calcitonin generelated peptide and its binding sites in the human central nervous system and pituitary. Proc Nall Acad Sci USA 1985;82:248.

6 Morris HR, Panico M, Etienne T, et al. Isolation and characterization of human calcitonin gene-related peptide. Nature 1984;308:746-8

\section{Thrombocytopenia induced by angiotensin} converting enzyme inhibitors

DrS B GROSBOIS, D MILTON, C BENETON, and D JACOMY (Department of Internal Medicine and Drug Surveillance Laboratory, Hopital Sud, Rennes, France) write: The angiotensin converting enzyme inhibitors are known to induce leucopenia and neutropenia,' particularly in patients with renal insufficiency and autoimmune diseases. Thrombocytopenia is usually associated with aplastic anaemia, ${ }^{2}$ but there are only two reports of pure thrombocytopenia. ${ }^{3+}$ Two sisters with idiopathic hypertension were treated with angiotensin converting enzyme inhibitors, which induced thrombocytopenia after nine days and eight weeks of treatment. We assessed the likelihood of drug induced thrombocytopenia using a scale for chronological $(\mathrm{C}=0-3)$ and semilogical $(\mathrm{S}=0-3)$ features produced by a French consensus meeting. ${ }^{+}$

Case 1-A 76 year old woman with no history of allergy or autoimmune disease was admitted in March 1985 with mucosal and cutaneous purpura which had appeared 24 hours earlier. A blood count showed severe and isolated thrombocytopenia $\left(1 \times 10^{9} / \mathrm{l}\right)$; a bone marrow aspirate showed megakaryocytes. She had received quinidine ( $100 \mathrm{mg} /$ day) since 1983 and enalapril $(20 \mathrm{mg} /$ day $)$ for the previous 10 days. After withdrawal of these drugs, a platelet transfusion, and treatment with prednisone ( $50 \mathrm{mg} /$ day for five days) her platelet count became normal $\left(229 \times 10^{9} / 1\right)$. HLA typing was A2 B8 DR3/A9 B13 DR7. She was discharged with no treatment and her platelet count remained 
normal over a month later. Rechallenge was not performed.

- Case 2-A 75 year old woman, the sister of the first patient and also with no history of allergy or autoimmune disease, was admitted in June 1986 with cutaneous purpura. She had a severe thrombocytopenia $\left(24 \times 10^{9} / 1\right)$, and a bone marrow aspirate showed nothing abnormal. Her only medication was captopril ( $25 \mathrm{mg} / \mathrm{day})$, which she had started taking in April. After withdrawal of captopril the platelet count returned to normal $\left(194 \times 10^{\circ} / 1\right.$ by August 1986$)$. HLA typing was A2 B8 DR3/A3 B14 DR-. No rechallenge was performed.

In both cases the score for drug induced thrombocytopenia was high (C2 S2), leading us to implicate the angiotensin converting enzyme inhibitors. Three points are worth underlining. Firstly, the haematological side effect in both cases was thrombocytopenia alone. Secondly, both sisters shared the B8 DR3 haplotype. In patients with rheumatoid arthritis adverse effects induced by gold salts, particularly haematological effects, are commoner in patients with B8 or DR3 allotypes. 5 Thirdly, the possible mechanism seems to be immunoallergic; in such a situation, and in contrast to leucopenia induced by captopril, rechallenge, even with small doses, is dangerous. These cases thus raise the possibility of a familial immunogenetic background that predisposes to drug induced side effects.

1 Case DB, Whitman H, Laragh JM, Spiera H. Successful low dose captopril rechallenge following drug induced leucopenia. Lancet $1981 ; \mathrm{i}: 1362$.

2 Al Matri A, Larabi MS, Kechrid C, Belkahia C, Ben Ayed H. Fatal bone marrow suppression associated with captopril. BrMed f 1981;283:27.

3 Walsh KP, Branagan J, Walsh MS. Reversible severe thrombocytopenia associated with captopril therapy. Ir Med f 1986; 79:43-4.

4 Khan MA, Bashi SA, Noah MS. Captopril associated isolated thrombocytopenia. Ir Med f 1987;80:101.

5 Solal-Celigny P, Benichou C, Boivin P, et al. Assessment criteria for drug induced granulocytic or platelet cytopenia: results of consensus meeting. Nouv Rev Fr Hematol 1987;29:265.

6 Adachi JD, Bensen WG, Singal DP, et al. Gold induced thrombocytopenia, platelet associated IgG and HLA typing in three patients. F R heumatol 1984;11:355-7.

\section{Fetal tachyarrhythmia and maternal antidepressant treatment}

Messrs A PRENTICE and R BROWN (Department of Obstetrics and Gynaecology, North Tees General Hospital, Stockton on Tees TS19 8PE) write: Tricyclic antidepressants taken in overdose can cause tachyarrhythmias in adults. We report a case in which a fetal tachyarrhythmia was believed to be related to maternal tricyclic treatment.

The patient was a 26 year old para $1+1$. After her first full term pregnancy she developed postnatal depression, which required drug treatment. She had no other relevant history. During the first trimester of her current pregnancy she developed a respiratory tract infection, which was treated with penicillin. She then complained of being depressed and was started on dothiepin hydrochloride, initially $50 \mathrm{mg}$ daily. This was increased to $75 \mathrm{mg}$ daily when she was about 16 weeks pregnant and subsequently reduced to 50 and $25 \mathrm{mg}$ daily at 30 and 34 weeks respectively. The general practitioner intended to discontinue treatment before term. An ultrasound scan performed shortly after 18 weeks confirmed gestational age and detected no abnormalities. No problems were detected at 28,30 , and 34 weeks, in particular no abnormalities of the fetal heart rate.

By 37 weeks there had been little growth over the preceding three weeks and her weight had remained static. On auscultation the fetal heart was irregular with a rate of over 180 beats $/ \mathrm{min}$. An ultrasound scan showed a normally grown fetus; the tachyarrhythmia was confirmed and there was no evidence of cardiac failure. She was admitted to the antenatal ward for observation. Over the next three days auscultation showed episodes of fetal tachyarrhythmia. Cardiotocographs performed at other times showed a normal baseline rate. The dothiepin was stopped. The frequency and the duration of the tachyarrhythmias decreased and within four days no abnormalities of the fetal heart rate were detected. At subsequent reviews in the antenatal clinic no abnormalities were noted on auscultation or on cardiotocography. The patient delivered a live male infant $(2980 \mathrm{~g})$ at term. Labour was uneventful, and the Apgar scores were 9 at 1 minute and 10 at 10 minutes. No abnormalities were detected on examination.

Dothiepin hydrochloride is not contraindicated in pregnancy, although there is no evidence of its safety and the datasheet advises that it should be used during pregnancy only "if there are compelling reasons.'

Tachycardia is a well recognised side effect of the tricyclic drugs, as are other disturbances of cardiac rhythm. In this case we presume that the fetal arrhythmia was related to maternal drug reatment: cessation of the treatment resulted in resolution of the episodes of fetal tachyarrhythmia. A Medline search and inquiries to both the drug's manufacturer and the Committee on Safety of Medicines disclosed no other cases. As fetal tachycardias may result in in utero cardiac failure al doctors should be aware of the potential consequences of prescribing tricyclic antidepressants to pregnant women. The advice of the datasheet to use these drugs in pregnancy only if there are compelling reasons should be heeded.

1 Maxwell DJ, Crawford DC, Curry PVM, Tynan MJ, Allan LD.
Obstetric importance, diagnosis, and management of fetal tachycardias. Br.Med f 1988;297:107-10.

\section{Acute pancreatitis associated with infusion of erythromycin lactobionate}

Dr Christopher R E HaWksworth (Department of Orthopaedic Surgery, Monklands District General Hospital, Airdrie ML6 0JS) writes: Acute pancreatitis is occasionally precipitated by drugs. I report a case that followed infusion of erythromycin lactobionate.

A 22 year old woman was admitted with suspected septic arthritis of the left hip. She felt unwell, had a temperature of $38^{\circ} \mathrm{C}$, and had been limping for a week. Hip movements were painfu and restricted. There was tenderness over the hip, but all other joints were unaffected. There was no family history of arthritides. Plain radiographs of the hip, full blood count, and serum calcium phosphate, and alkaline phosphatase values were all normal, but the erythrocyte sedimentation rate was $39 \mathrm{~mm}$ in the first hour. Blood cultures proved sterile.

As she claimed to be allergic to penicillins erythromycin and fucidic acid were prescribed. Since the fucidic acid was not immediately available treatment was started with an infusion of erythromycin lactobionate (Abbott Laboratories) $2 \mathrm{~g}$ in $500 \mathrm{ml}$ of isotonic saline to run over one hour Soon after the infusion started the patient began to feel nauseated and within 40 minutes had developed severe epigastric pain, which radiated to her back. The infusion was stopped. Examination of the abdomen showed nothing abnormal apar from acute epigastric tenderness. Full blood coun and urea and electrolyte measurements were normal, but serum amylase activity was raised $(610 \mathrm{IU} / \mathrm{l})$. The pain settled with appropriate analgesia but recurred later that night, when an amylase activity of $5240 \mathrm{IU} / \mathrm{l}$ confirmed pancreatitis. Blood glucose, calcium, urea, and electrolyte concentrations and arterial blood gas pressures were all normal. There was only minimal disturbance of liver function tests.
She was managed conservatively with nasogastric aspiration, intravenous fluids, and analgesia as needed. Clinically she improved and within five days her blood biochemistry profile had returned to normal. She denied any recent viral illness or alcohol abuse and had not been taking any other medication. There was no history of pancreatitis or biliary disease. The liver, pancreas, and biliary tract were normal on ultrasonography. The suspected hip infection resolved with gentamicin and at three months she had had no further episodes of hip or pancreatic pain

Drug associated pancreatitis is rare.' There have been no published reports linking erythromycin infusion with pancreatitis and the manufacturer knows of no cases. Erythromycin can cause ab dominal pain, jaundice, and hepatocellular toxicity (prescribing information, Abbott Laboratories) and the cramp-like abdominal pains are relieved by antispasmodic agents, suggesting a direct action on smooth muscle in the gut. ' If this were so spasm of the sphincter of Oddi and subsequent bile reflux into the pancreatic duct may have initiated pancreatitis in this case.

Serious complications from drug induced pancreatitis are rare," and it should have been possible to confirm the causal relation between the drug infusion and the pancreatitis by rechallenge. As alternative drugs were available to treat the initial complaint we did not feel this could be justified.

1 Mallory A, Kern F. Drug induced pancreatitis: a critical review. Gastroenterolog 1980; $78: 813-20$.

2 Putzi R, Blaser J, Luthy R, et al. Side effects due to the intravenous infusion of erythromycin lactobionate. Infection 1983;11:161-3.

3 Steinberg WM. Acute drug and toxin induced pancreatitis. Hospital Practice 1985;20:95-105.

\section{An allergy to Marmite?}

Dr NIGEL HIGSON (Hove BN3 3DX) writes: Dr Janice Main and colleagues implicate an antibody to bakers' yeast in the development of Crohn's disease.' Yeast may also be implicated in the development of other immune responses. I describe here a case of allergy to a food containing yeast extract (Marmite) which does not seem to have been described in the medical journals (a Medline search revealed no references), yet it seems a common and frightening occurrence, particularly in very young children.

The patient was a 15 month child who apart from having Down's syndrome and an atrioventricular defect was well at the time and had no history of allergy. Marmite was given thinly spread on buttered white bread. Within five minutes mild angio-oedema of the lips and periorbital tissues had occurred. This caused no difficulty in breathing and subsided within 60 minutes. The link with Marmite was not recognised and some days later the child was again given some on bread. This time a more dramatic reaction occurred with a greater degree of angio-oedema of the mouth and periorbital tissues such that the child exhibited some difficulty in respiration. Most of the oedema settled again within 60 minutes and the child did not require drug treatment. On talking to other parents of young children I found that several other children exhibit similar reactions to Marmite and, although I know of no major anaphylactic reaction occurring, the angio-oedema is sufficiently severe to cause concern to the parent. Should such products be promoted as a weaning food? Some health visitors advise mothers to put Marmite on their nipples to break the child's breast feeding habit; in a susceptible child this action might possibly be fatal.

I Main J, Mlckenzie H, Yeoman GR, et al. Antihede to Saccharome 1988:297:1105-6. 290ctober. 